\title{
Light Perception: A Sestina
}

\author{
Christos Theophanous, MD
}

Department of Ophthalmology and Visual Science, University of Chicago, Chicago, IL, USA.

$\mathrm{J}$ Gen Intern Med 35(12):3715

DOI: $10.1007 / \mathrm{s} 11606-020-06223-0$

(C) Society of General Internal Medicine 2020

She already knows. She hears it in the pounding quiet that blankets the sterile room as he slides his light left and right, peering deep into the dark hole of her eyes until it catches the reddish glow in the face of the battered lens clutched between his fingers.

He inches the instrument forward, his fingers guiding a careful view of her quiet eye, peering past her yellowed lens to find the hollowed nerve centered in his light, like a dull streetlamp casting its pale glow though a deep night's dark.

Pulling the lens away, the eye again becomes dark. He pauses a moment, rolling it between his fingers, casting a circular shadow in the slit lamp's glow as he ponders a moment, afraid to break the quiet. He nudges the scope aside, extinguishes its light, and pockets his lens.

She feels the cold touch of the lens pull away from her eyelid as she settles back into the dark. Faint colors linger from the quenched light. She already knows his verdict. She just waits, fingering a stitched edge of her chair in the thick quiet watching the few remaining embers glow.
In a moment, they lose their final glow leaving her with the tinkling sound of the lens rattling on the linoleum floor, cutting the quiet. He rummages across the room in the dark, feeling along the wall until his fingers find the switch and fill the room with light.

He shifts his stool beside her and places a light hand on her shoulder. A faint smile glows on her face as she places wrinkled fingers on his. She's known this pattern, his lamp and lens, for as long as they've fought this insidious dark.

But this time, he saves his words to preserve the quiet.

There is comfort in the quiet and no more he can do to bring back the light.

She rises to her feet in the now familiar dark and heads towards the doorway's dim glow.

His fingers guide her from the room, away from the doused lamp and the ineffectual lens.

Prologue: The sestina is a fixed verse form dating back to the $12^{\text {th }}$ century that contains six stanzas of six lines each and a seventh stanza of three lines. Every line ends with one of six words that are repeated in a specific pattern. In this piece, the use of the structured sestina form plays on the formulaic and routine nature of a patient encounter and contrasts it with the personal and emotional facets of the patient-physician relationship.

Received April 21, 2020

Accepted September 7, 2020

Published online September 28, 2020

Corresponding Author: Christos Theophanous, MD; Department of Ophthalmology and Visual Science, University of Chicago, Chicago, IL, USA (e-mail: cntheoph@gmail.com).

Publisher's Note: Springer Nature remains neutral with regard to jurisdictional claims in published maps and institutional affiliations. 